\title{
THE EFFECT OF FOOD AND WATER DEPRIVATION (STRESS) ON SALMONELLA-CARRIER MICE
}

\author{
G. W. Tannock and J. M. B. Smith \\ Department of Microbiology, University of Otago, Dunedin, New Zealand
}

OUtBREAKS of salmonellosis among domestic animals seem to be precipitated in many cases by environmental "stress" such as a sudden change of diet, holding in yards, and transport. Under such conditions, some salmonellacarrier animals become clinical cases (Salisbury, 1958). Circumstantial evidence suggests that stress is also important in the build-up of infection between farm of origin and slaughter, and results in the excretion of increased numbers of salmonellae by infected animals (Williams and Newell, 1968); this may cause contamination of the environment and increased transmission of infection to other animals.

Recently we have induced an experimental salmonella-carrier state in mice by intranasal inoculation of a small dose of organisms (Tannock and Smith, 1971). Using this experimental model, we have been able to investigate the fate of salmonellae residing within asymptomatic carrier-animals during stress by deprivation of food and water. This paper records the results.

\section{MATERIALS AND METHODS}

\section{Cultures}

Two strains of Salmonella were used-S. typhimurium no. 573 (phage type 1), and S. typhimurium no. 758 (phage type 1a). Both strains had been isolated from sheep, and had an LD50 for mice by intraperitoneal inoculation of $4 \times 10^{7}$ and $4 \times 10^{6}$ cells respectively. Washed, diluted, $18-24 \mathrm{hr}$ cultures at $40^{\circ} \mathrm{C}$ in nutrient broth were administered to 16 -wk-old mice by the intranasal-drop method: $0.02 \mathrm{ml}$ of saline containing about $2 \times 10^{3}$ salmonellae was placed over the nasal orifices of each anaesthetised mouse. The inoculum was inhaled by the normal respiratory action of the animal.

\section{Experimental procedures}

Three experimental methods were used.

Experiment 1. After inoculation the mice were maintained in individual cages on wood shavings and supplied with commercial pellets and water ad libitum for 12 days. Food, water and shavings were then removed from the cages for 3 days. Groups of seven mice that had been inoculated with strain no. 573, or groups of three mice inoculated with strain no. 758 , were killed and examined just before food and water deprivation, and at 1,2 and 3 days after stress was initiated. Food, water and shavings were returned to the cages at the end of the stress period, and similar groups of animals were examined at 1, 2, 7 and 14 days after the conditions of stress had been ended.

Experiment 2. The same procedure was followed except that the mice were kept in cages with wire grids instead of shavings. Faecal pellets passed through the grids and were not available for ingestion by the mice. The animals were examined in groups of three.

Revised version received 27 Sept. 1971; accepted 7 Dec. 1971. 
Experiment 3. Groups of ten animals were treated as in experiment 2 except that they were killed and examined 21 days after the stress conditions had been ended. A control group of inoculated unstressed animals was maintained and examined similarly.

\section{Examination of inoculated mice}

Experiments 1 and 2. The stomach, small intestine, caecum +large intestine, spleen, and lungs were removed from each animal, washed in $2-3 \mathrm{ml}$ of saline, and homogenised by pestle and mortar with $5 \mathrm{ml}$ of sterile saline and some sterile sand. Of the resulting suspensions (or serial ten-fold saline dilutions thereof) $0.1 \mathrm{ml}$ was spread over the surface of brilliant green-agar medium containing sodium sulphadiazine $80 \mathrm{mg}$ per 1 . The remaining suspension was added to $10 \mathrm{ml}$ of tetrathionate broth containing brilliant green 1 in 100,000 and sodium sulphadiazine $80 \mathrm{mg}$ per 1 . After incubation, the enrichment broths were subcultured on brilliant green-sulphadiazine agar. All cultures were incubated at $40^{\circ} \mathrm{C}$ for $24-48 \mathrm{hr}$. Colony counts were made on the direct plates, and the numbers of viable salmonellae per organ were calculated. In addition, the gall bladder, mesenteric lymph-nodes, and $0.1 \mathrm{ml}$ of blood from the axillary vessels were examined qualitatively by enrichment in tetrathionatebrilliant green-sulphadiazine broth and subculture to brilliant green-sulphadiazine agar.

Saline washings were obtained from the upper respiratory tract by insertion of a blunted bent needle attached to a syringe into the nasopharynx of each animal and injection of $0.5 \mathrm{ml}$ of saline through the upper respiratory tract and out the nostrils. These washings were cultured qualitatively.

Characteristic colonies of Salmonella that developed on brilliant green-sulphadiazine agar were checked by slide agglutination.

Experiment 3. The caecum + large intestine, mesenteric lymph-nodes, and spleen were removed from each mouse as described above. The specimens were cut up finely and cultured qualitatively as above. Upper respiratory-tract washings were also obtained from each animal and examined similarly.

Titrations of antibody. All mice were anaesthetised and bled from the axillary blood vessels before necropsy. Pooled sera from each group of mice were examined for antibodies against the inoculated strain of Salmonella by an indirect-haemagglutination technique with ovine erythrocytes coated with the appropriate antigenic material (Jonas, 1967).

\section{RESULTS}

\section{Experiments 1 and 2}

The results obtained from the cultural examination of stomach, small intestine, and caecum + large intestine of mice inoculated with strain no. 758 are shown in figs. 1 and 2. Similar results were obtained with strain no. 573.

Table I shows the results obtained from the examination of lungs, spleen, upper respiratory-tract washings, mesenteric lymph-nodes, and gall bladder from mice given strains 758 and 573 and maintained on wire grids. Little increase in the numbers of salmonellae in the lungs and spleen was apparent during the stress period, and similar results were obtained from mice maintained on shavings. Most of the mice examined harboured salmonellae in the upper respiratory tract throughout the experimental period. Salmonellae were present in most mesenteric lymph-nodes from mice given strain no. 758 even before the stress began, but lymph-nodes from mice given strain no. 573 only occasionally contained these organisms from 3 days of stress onwards. Salmonellae could be recovered more regularly from the gall bladders of mice given strain no. 758 than from those given strain no. 573, especially during the stress period. 
Salmonellae were isolated from one blood sample obtained from a mouse given strain no. 758 and stressed for 2 days. No deaths were recorded among the mice in the experimental groups described above.

Serological examination of mice showed that detectable amounts of antibody were not present until 1-2 wk after the end of the stress period. At this stage titres were 1 in $2-8$.

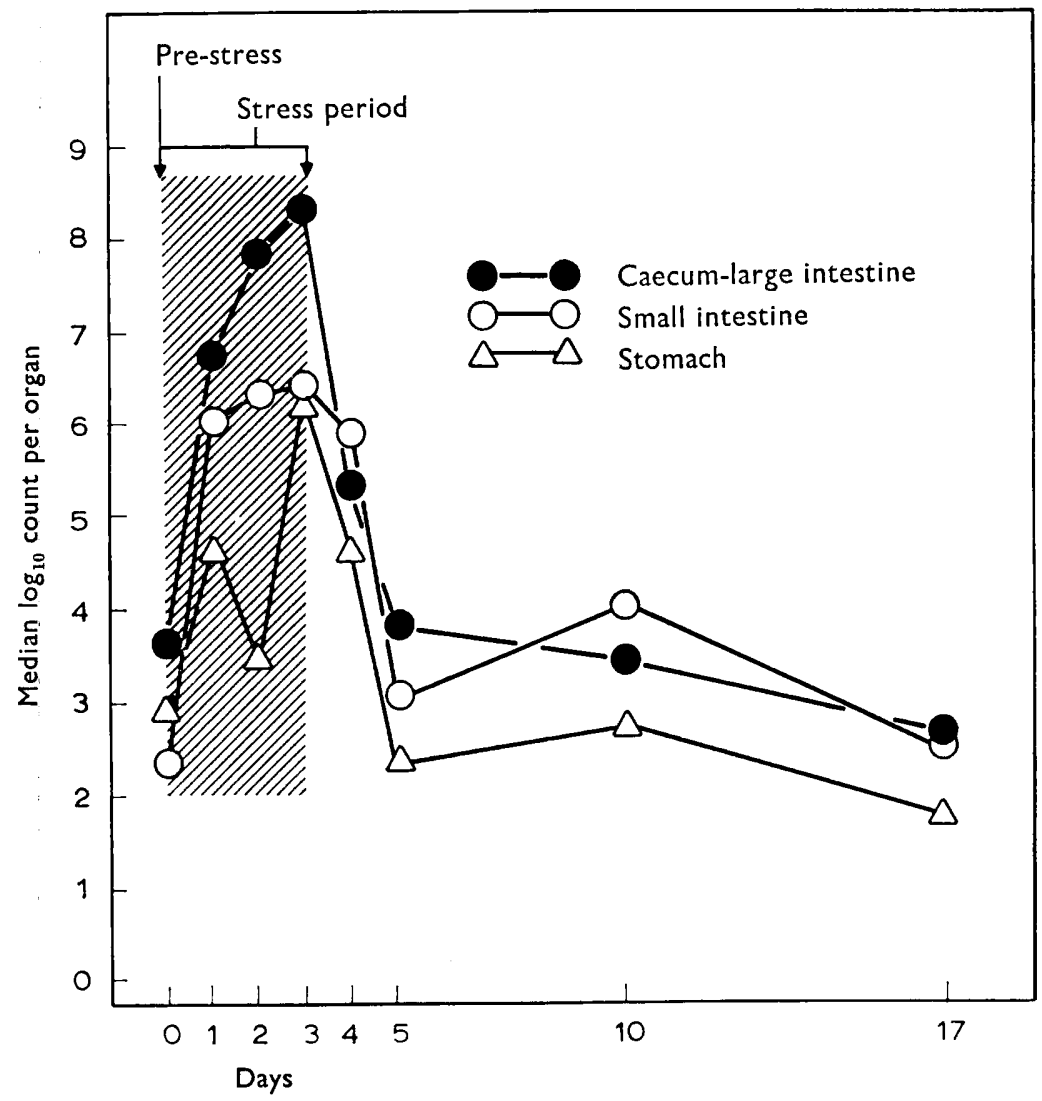

FIG. 1.-Experiment 1. Effect of deprivation of food and water (stress) on mice that had been given c. $2 \times 10^{3} S$. typhimurium, strain no. 758 , intranasally 12 days before, and were maintained on wood shavings. Mice examined in groups of three.

\section{Experiment 3}

In the experiments in which mice were observed for 21 days after the stress period, two of the ten animals given strain no. 758 died 1 day after the end of the stress period; salmonellae were isolated from all organs examined from these two mice. Of the ten animals given strain no. 573 and stressed, none died during the period of observation. Of the mice that were given these strains, but were not stressed, all survived the observation period. The isolations of Salmonella from the survivors of stressed and non-stressed groups are shown in 
table II, together with the antibody titres in the pooled sera of these animals. A significant difference of antibody titre between non-stressed and stressed animals infected with strain no. 573 was observed. No such difference was observed in animals infected with strain no. 758 .

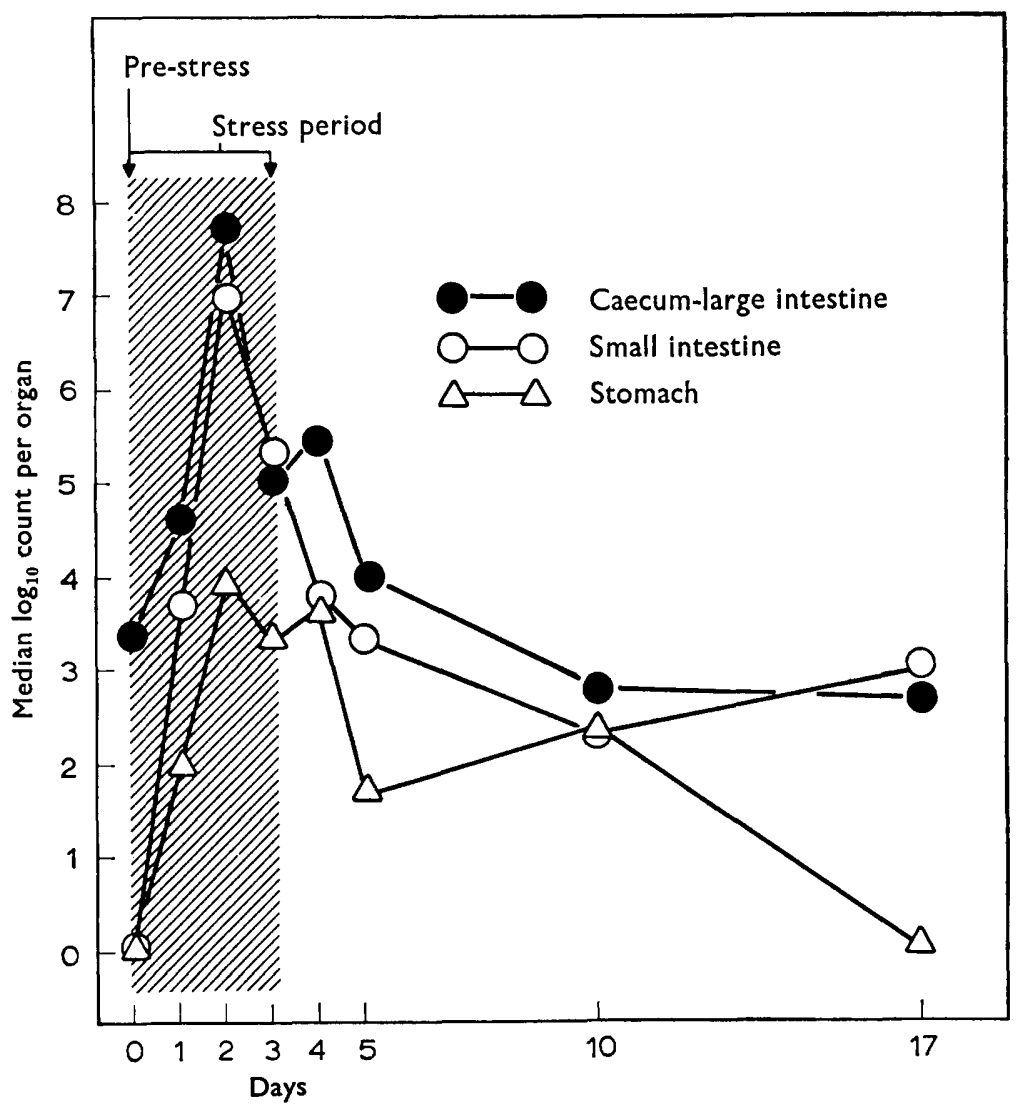

FIG. 2.-Experiment 2. Effect of deprivation of food and water (stress) on mice that had been given c. $2 \times 10^{3} S$. typhimurium, strain no. 758 , intranasally 12 days before, and were maintained on wire grids. Mice examined in groups of three.

\section{Discussion}

The results show highly significant increases in the numbers of salmonellae present in the stomach, small intestine, and caecum + large intestine of animals subjected to the stress of food and water deprivation. The highest numbers were generally found in these organs after $2-3$ days' stress, but when food and water were again available, the numbers of salmonellae decreased to about prestress levels, though the small intestine generally continued to harbour a somewhat larger population of Salmonella.

It seems that changes within the carrier animal due to deprivation of food and water allowed the multiplication of salmonellae to occur throughout the gastro-intestinal tract. This led to the death of some of the carrier animals. 


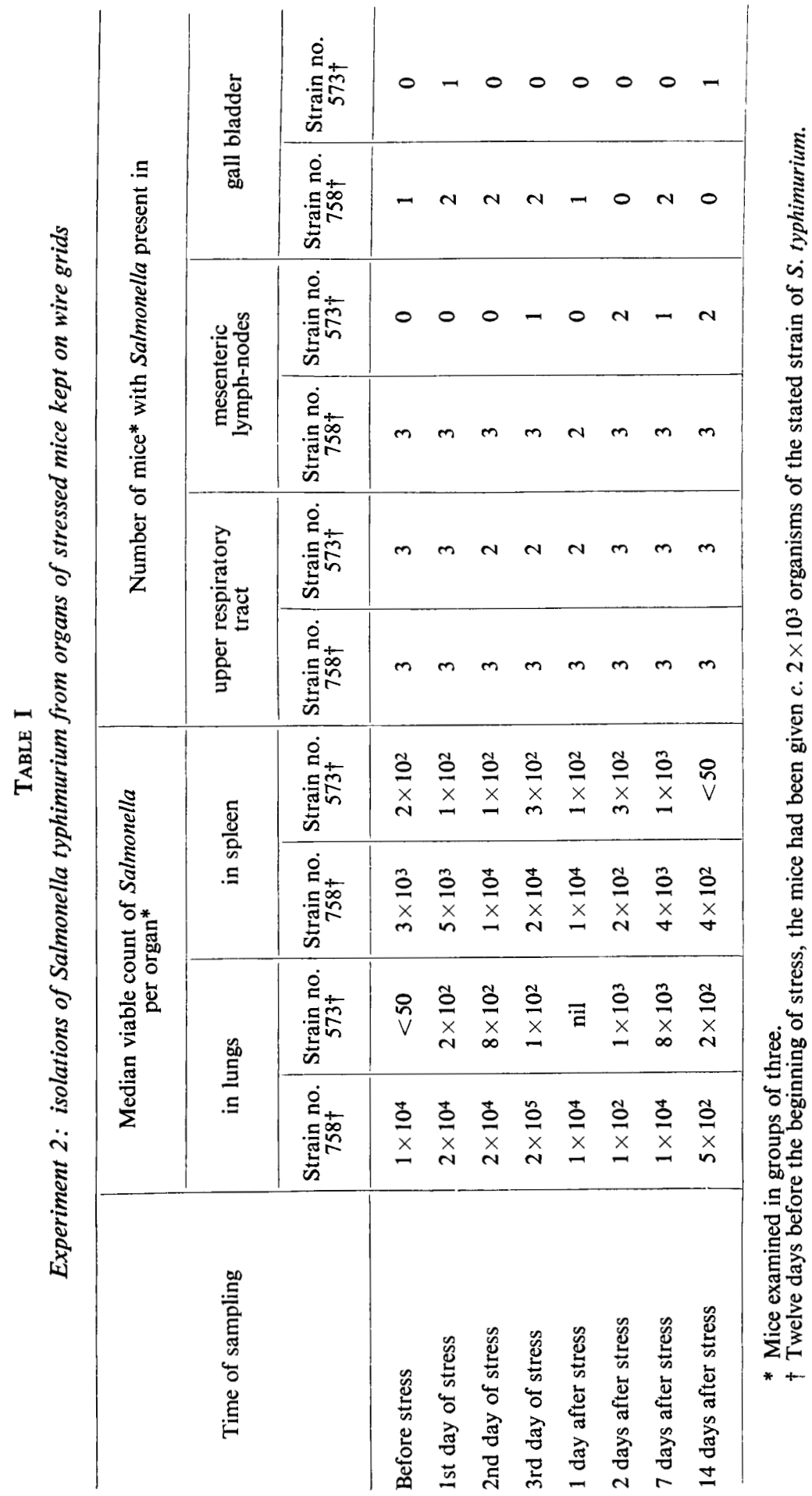


Even though the Salmonella strain was not of sufficient virulence to cause the death of more than a few animals, other stressed carriers still harboured increased numbers of salmonellae.

From our results it seems that the apparent build up of salmonella infection recorded between farm and abattoir (Galton et al., 1954; Nottingham and Urselmann, 1961), might be explained by multiplication of salmonellae in the gastro-intestinal tract of stressed carrier-animals. As well as increasing the likelihood of detecting carriers, this multiplication within the gut undoubtedly causes increased contamination of the environment. Opportunity for crossinfection between animals is thus greatly enhanced.

TABLE II

Experiment 3: Salmonella carriage in mice examined 21 days after the end of stress

\begin{tabular}{l|c|c|c|c}
\hline & $\begin{array}{c}\text { Survivors of stressed mice: } \\
\text { number harbouring Salmonellal } \\
\text { number examined, after } \\
\text { inoculation of strain no. }\end{array}$ & $\begin{array}{c}\text { 年 } \\
\text { number harbouring Salmonellal } \\
\text { number examined, after } \\
\text { inoculation of strain no. }\end{array}$ \\
\hline & 758 & 573 & 758 & 573 \\
\hline Upper respiratory-tract & $5 / 8$ & $5 / 10$ & $7 / 10$ & $6 / 10$ \\
Spleen & $0 / 8$ & $1 / 10$ & $0 / 10$ & $0 / 10$ \\
Caecum+large intestine & $2 / 8$ & $5 / 10$ & $6 / 10$ & $4 / 10$ \\
Mesenteric lymph-nodes & $7 / 8$ & $5 / 10$ & $6 / 10$ & $1 / 10$ \\
\hline Reciprocal of serum-antibody & $2,4,4$ & $8,32,64$ & $2,2,16$ & $\mathrm{n} 2^{*}, 2,4$ \\
\hline titre (three serum pools) & & & & \\
\hline
\end{tabular}

$* \mathrm{n} 2=$ negative at 1 in 2.

In New Zealand at least, confinement of animals in yards at the farm of origin, transport for long distances to abattoirs or meat works, and holding at the works before slaughter, may involve deprivation of food and water for 2 or 3 days. The stress imposed on carrier mice in this investigation was therefore not unrealistic in terms of the conditions that exist in the field. The few deaths occurring in the group of stressed mice in this investigation paralleled the situation found under natural conditions in which only a few of the infected animals die (Robinson and Royal, 1971; Tannock et al., 1971). The results obtained from mice therefore seem relevant to the situation found in farm animals.

The changes within the host that allow the increased multiplication of salmonellae during stress can now be examined in this experimental model.

\section{SUMmaRY}

The effect of food and water deprivation (stress) on asymptomatic carriage of Salmonella was investigated in mice given Salmonella typhimurium intranasally. Groups of mice were killed and examined by cultural and serological 
techniques before, during, and after a 3-day stress period. The numbers of salmonellae in the stomach, small intestine, and caecum+large intestine increased during the stress period, with the greatest increases occurring after 2-3 days. Stress-induced changes within the carrier animal apparently allow the multiplication of salmonellae to occur throughout the gastro-intestinal tract.

We wish to thank Professor J. A. R. Miles, Department of Microbiology, University of Otago, for the provision of facilities.

\section{REFERENCES}

Galton, Mildred M., Smith, W. V., McElrath, H. B., ANd Hardy, A. B. 1954. Salmonella in swine, cattle and the environment of abattoirs. J. Infect. Dis., 95, 236.

JoNAS, W. E. 1967. Salmonellosis of sheep: use of serum from a vaccinated ewe in a mouse passive protection test. N.Z. Vet.J., 15, 55 .

Nottingham, P. M., and UrselmanN, A. J. 1961. Salmonella infection in calves and other animals. N.Z. Jl. Agric. Res., 4, 449.

Robinson, R. A., AND Royal, W. A. 1971. Field epizootiology of Salmonella infection in sheep. N.Z. Jl. Agric. Res., 14, 442.

Salisbury, R. M. 1958. Salmonella infections in animals and birds in New Zealand. N.Z. Vet. J., 6, 76.

Tannock, G. W., McInnes, H., Shirley, G., and Smith, J. M. B. 1971. Salmonellosis in sheep wintered outdoors on straw and sawdust pads. N.Z. Vet.J., 19, 29.

TANNOCK, G. W., AND SMITH, J. M. B. 1971. A Salmonella carrier state involving the upper respiratory tract of mice. J. Infect. Dis., 123, 502.

Williams, L. P., JR, AND Newell, K. W. 1968. Sources of salmonellas in market swine. J. Hyg., Camb., 66, 281. 